\begin{tabular}{|l|l|l|}
\hline \multicolumn{2}{|c|}{ PublisherInfo } \\
\hline \hline PublisherName & $:$ & BioMed Central \\
\hline \hline PublisherLocation & $:$ & London \\
\hline \hline PublisherImprintName & $:$ & BioMed Central \\
\hline \hline
\end{tabular}

\title{
A circadian clock in the cardiovascular system
}

\begin{tabular}{||l|l|l||}
\hline \multicolumn{2}{|c||}{ ArticleInfo } \\
\hline \hline ArticleID & $:$ & 4142 \\
\hline \hline ArticleDOI & $:$ & $10.1186 /$ gb-spotlight-20010710-02 \\
\hline \hline ArticleCitationID & $:$ & spotlight-20010710-02 \\
\hline \hline ArticleSequenceNumber & $:$ & 213 \\
\hline \hline ArticleCategory & $:$ & Research news \\
\hline \hline ArticleFirstPage & $:$ & 1 \\
\hline \hline ArticleLastPage & $:$ & 4 \\
\hline \hline & & RegistrationDate : 2001-07-10 \\
ArticleHistory & $:$ & OnlineDate \\
\hline \hline ArticleCopyright & $:$ & BioMed Central Ltd2001-07-10 \\
\hline \hline ArticleGrants & $:$ & \\
\hline \hline ArticleContext & $:$ & 130592211 \\
\hline \hline
\end{tabular}




\section{Simon Frantz}

Email: simonfrantz@hotmail.com

Researchers have made important progress in understanding how circadian rhythms might be controlled in the cardiovascular system and other organs throughout the body. In the June 29 issue of Cell, McNamara et al. reveal that blood vessels contain their own circadian system, and provide the first evidence that hormones and vitamins could regulate this clock's rhythm.

All eukaryotes display changes in biochemical or physiological behaviour that are governed by the day/night cycle; for example, melatonin levels rise during the night and falling during the day. The 'master clock' in humans is situated in the suprachiasmatic nucleus $(\mathrm{SCN})$, an area of the brain that consists of a cluster of around 10,000 neurons synchronized to fire rhythmically and generate a coordinated circadian rhythmic output.

One of the most intensive areas of biological research has involved discovering the factors that drive these circadian rhythms. Studies have found interacting positive and negative transcriptionaltranslational feedback loops are important. The best-characterized feedback loop in the mouse involves the regulation of three Period genes (mPER1-mPer 3$)$ and two Cryptochrome genes ( $m C R Y 1$ and $m C R Y 2)$.

Transcription of $m P e r$ and $m C r y$ genes is thought to be driven by accumulating heterodimers of the CLOCK and BMAL(MOP3) proteins; the heterodimers activate the genes by binding to consensus Ebox elements. Subsequently, complexes of mPER and mCRY proteins enter the nucleus, where they shut off CLOCK-BMAL1-mediated transcription. At the same time, mPER2 upregulates levels of Bmall RNA (by a currently unknown mechanism), leading to the formation of CLOCK:BMAL1 heterodimers which drive $m P e r / m C r y$ transcription and restart the cycle.

Recently, molecular clocks have also been uncovered in peripheral tissues, such as the liver, kidney and heart. Circadian rhythms in $m P e r$ RNA abundance had been observed, although their phase of oscillation is delayed three to nine hours relative to the oscillation in the SCN. Studies on both isolated cells and SCN-deficient animals suggested that these peripheral oscillations might be driven or synchronized by the SCN, while other findings indicated that humoral signals could be involved, although the mechanism was poorly understood.

This led researchers to investigate blood pressure, because it exhibits a circadian variability that is exaggerated in patients who have high blood pressure - suggesting that the mechanisms controlling this rhythm are disturbed. This could have physiological consequences because heart attacks and strokes most commonly occur early in the morning, when blood pressure levels are at their highest during the 24 hour cycle.

"When the blood pressure peaks, various processes are occurring, for example, people are getting up and their hormone levels are rising," explained Garret FitzGerald, chairman of the Department of Pharmacology, University of Pennsylvania and author of the new study. "This suggests there could be some form of integrator - something transmitting from the master clock to the peripheral organs."

They uncovered a clue to a potential mechanism when they discovered a circadian variability in the local vascular response to hormones that affect blood pressure. In addition, other recent studies had 
found that circulating concentrations of some steroids undergo circadian variability and examples of hormonal phase-shifting of circadian genes in peripheral organs were beginning to emerge. This was considered interesting because steroid hormones and vitamins regulate developmental and physiological processes by activating intracellular members of the nuclear receptor superfamily, which function as ligand-dependant DNA-binding transcription factors.

One potential candidate class of chemicals for this form of regulation was the retinoids, which act through retinoic acid receptors (RAR) and retinoid X receptors (RXR). In contrast to steroid receptors, which typically act as homodimers, RXRs form heterodimers with many members of the same family, such as RARs. When the University of Pennsylvania team used the ligand-binding domain of human RXR as 'bait' in a yeast two-hybrid protein-protein interaction screen, they found that it bound with a protein called MOP4, which was very similar at the amino acid level to CLOCK. Just like CLOCK, MOP4 forms heterodimers with BMAL1, promotes E-box-mediated activation of genes, such as Per I and vasopressin, and is negatively regulated by CRY 1 and CRY2.

But previous studies had shown almost no expression of MOP4 in the SCN, and it had, therefore, not been considered to play an important role in the core circadian feedback loop. To see whether MOP4 was rhythmically expressed in the vasculature, the group carried out RNase protection assays on human vascular smooth muscle cells (hVSMCs) after serum shock, which is known to reset and stimulate the circadian system. They found that Mop 4 mRNA levels cycled in a circadian pattern, peaking at 28 and 52 hours.

To prove this phenomenon occurred in vivo, the group measured the expression of Mop4 from aorta harvested at four-hour intervals over a 48-hour period from Balb/c mice maintained either in 12-hour light/dark cycles or in constant darkness. Mop4 RNA showed a cyclical pattern of expression under both conditions. Looking at the expression of other genes showed that Bmall and Per2 expression had a similar pattern, but Per2 was antiphase to Mop4. This suggested the existence of a vascular clock, where MOP4:BMAL1 heterodimers drive Per2 mRNA.

But what drives MOP4? Ligand-bound nuclear receptors interact with CLOCK and MOP4 to prevent their E-box-mediated gene activation, which implies circadian variability in steroid hormones and vitamins, such as retinoids, might phase shift or reset a peripheral clock in the vasculature. When seruminduced hVSMCs were given all-trans retinoic acid (tRA), the $h P e r 2$ oscillation was delayed by four hours. And when mice maintained in constant darkness were injected intraperitoneally with tRA, the $m P e r 2$ peak was delayed in both the aorta and heart by three hours.

This, according to FitzGerald, suggested that RXRa and RARa play novel roles in the negative arm of the circadian feedback loop by binding to CLOCK and MOP4 and preventing their ability to drive E box mediated Per transcription. "The key findings are two-fold," he explained. "Firstly, this shows there is a circadian system in the vasculature, which suggests this could also be occurring in all peripheral organs. And secondly, this shows a mechanism by which hormones can regulate a peripheral clock."

A peripheral clock for the vasculature probably evolved to protect the blood supply to organs from large shifts in blood pressure, such as exercise or adrenaline rushes, he surmised. One of the important implications of the findings is that they might explain how overlaying aspects such as posture and stress affect blood pressure levels. 
Identification of the range of genes involved in the vascular response could have an important impact on drug research and treatment. "We know that the response to certain drugs used in the treatment of cancer varies substantially depending on the time of day they are administered. If you knew exactly what component needs to be regulated to reset the clock, you could target this with drugs," FitzGerald concluded.

\section{References}

1. Circadian rhythms: how they affect our health, [http://www.hallym.ac.kr/ neuro/kns/tutor/medical/ rhy.html]

2. McNamara P, Seo S-B, Rudic RD, Sehgal A, Chakravarti D, FitzGerald GA: Regulation of CLOCK and MOP4 by nuclear hormone receptors in the vasculature: a humoral mechanism to reset a peripheral clock. Cell 2001, 105:877-899., [http://www.cell.com/]

3. Circadian rhythms, [http://www.ultranet.com/ jkimball/BiologyPages/C/Circadian.html]

4. Hastings M.: Clinical Review: The brain, circadian rhythms, and clock genes. $B M J 1998$, 317:1704-1707., [http://www.bmj.com/cgi/content/full/317/7174/1704]

5. Beevers G, Lip GYH, O'Brien E.: ABC Hypertension: The pathophysiology of hypertension. $B M J$ 2001, 322: 912-916., [http://www.uib.no/med/avd/physiol/tenstad/forelesninger/pdf/

ABC_hypertension.pdf]

6. Department of Pharmacology, University of Pennsylvania, [http://www.med.upenn.edu/ pharm/] 